\title{
Factors associated with cutaneous ulcers among children in two yaws-endemic districts in Ghana
}

\author{
Rafiq Nii Attoh Okine ${ }^{1}$, Bismark Sarfo ${ }^{2}$, Richard M. Adanu ${ }^{2,3}$, Cynthia Kwakye-Maclean ${ }^{4}$ and Francis Adjei Osei ${ }^{5,6^{*}}$ (D)
}

\begin{abstract}
Background: Yaws is a chronic relapsing disease caused by Treponema pallidum subspecies pertunue, which can result in severe disability and deformities. Children below the age of 15 years in resource-poor communities are the most affected. Several non-specific factors facilitate the continuous transmission and resurgence of the disease. Endemic communities in rural Ghana continue to report cases despite the roll out of several intervention strategies in the past years. The objective of this study was to determine the factors associated with cutaneous ulcers among children in two yaws-endemic districts in Ghana.
\end{abstract}

Methods: A community-based unmatched 1:2 case-control study was conducted among children between 1 and 15 years. Data on socio-demographic, environmental and behavioral factors were collected using a structured questionnaire. Active case search and confirmation was done using the Dual Path Platform (DPP) Syphilis Screen and Confirm test kit. Data were analyzed using STATA 15. Logistic regression was done to determine the exposures that were associated with yaws infection at 0.05 significant level.

Results: Sixty-two cases and 124 controls were recruited for the study. The adjusted multivariable logistic regression model showed that yaws infection was more likely among individuals who reside in overcrowded compound houses $(\mathrm{aO} R=25.42$, 95\% Cl: 6.15-105.09) and with poor handwashing habits ( $a O R=6.46,95 \%$ Cl: $1.89-22.04)$. Male (aOR=4.15, 95\% Cl: 1.2913.36) and increasing age $(a O R=5.90,95 \%$ Cl: 1.97-17.67) were also associated with yaws infection.

Conclusions: Poor personal hygiene, overcrowding and lack of access to improved sanitary facilities are the factors that facilitate the transmission of yaws in the Awutu Senya West and Upper West Akyem districts. Yaws was also more common among males and school-aged children. Improving living conditions, access to good sanitary facilities and encouraging good personal hygiene practices should be core features of eradication programs in endemic communities.

Keywords: Yaws, Dual path platform, Upper west Akyem, Awutu Senya west, Children

\section{Background}

Yaws is one of the three non-venereal treponemal diseases that is considered as a neglected tropical disease (NTD) [1]. The disease is caused by Treponema pallidum subspecies pertenue. It is a highly contagious disease which has a

\footnotetext{
*Correspondence: francisph1@hotmail.com

${ }^{5}$ Public Health Unit, Komfo-Anokye Teaching Hospital, Kumasi, Ghana

${ }^{6}$ KNUST School of Public Health, Kumasi, Ghana

Full list of author information is available at the end of the article
}

chronic relapsing pattern [2]. Yaws is transmitted through skin-to-skin contact and primarily affects children under the age of 15 years typically in areas of low socioeconomic status and sanitation challenges. The disease is endemic in low-to-middle income countries and resurgence has been reported in the Pacific region, West and Central Africa and Southeast Asia [3]. The disease is usually self-limiting but can lead to severe complications involving the skin and bones. Typically, this results in 
destructive lesions of bones and cartilages and results in severe deformities and disability [4].

Despite concerted efforts and strategies to eradicate yaws, the disease is still endemic in at least fourteen countries [1]. A systematic review published in 2015, estimated that over 80 million people were living in endemic districts [2]. Over 250000 cases of yaws were reported between 2010 and 2013 to the World Health Organization (WHO) from endemic countries [2]. Eighty-four (84) percent of the cases were from Ghana, Papua New Guinea and Solomon Island [2].

Ghana is among the countries in sub-Saharan Africa with increased prevalence of yaws. There are case reports of yaws in all the 16 regions with $160 / 170$ health districts reporting cases [2]. In the last 8 years, averagely, 111 cases per 100000 population/year were reported in the country [5]. Rural communities in Ghana continue to report new cases despite variety of strategies that have been implemented over the past years. A national school-based survey reported a prevalence of $20 \%$ amongst school children [6]. The Central, Eastern and Volta Regions remain endemic, reporting between 5.0338 cases/100 000 population over a 4-year period [5].

WHO launched the Morges Yaws Eradication Strategy in 2012, with a target of eradication by 2020. A major component of the new strategy was the change from the injectable benzathine penicillin to oral azithromycin [7]. The new treatment strategy was piloted in three countries including Ghana [8-10] and though the strategy had significant impact on disease burden, it did not achieve elimination targets in high endemic communities [11]. This is a major pointer to further explore the environmental drivers of yaws transmission in highly endemic communities.

The National Yaws Eradication Program (NYEP) in Ghana, which was set up in 2008 has the singular task of co-coordinating all yaws activities in the country through collaboration with international agencies. The program had set elimination targets by the end of 2017 (zero indigenous cases from a baseline of 29 cases/ 100000 population/year over the last 5 years) and total eradication by 2020 [12]. Ghana is likely to miss these targets due to multiplicity of factors including resource limitation to scale up integrated interventions and gaps in the understanding of the disease transmission process accounting for resurgence of the disease in some endemic districts.

Myriad of factors are known to be associated with yaws transmission. Personal factors (age, sex and cultural beliefs), behavioral factors (such as personal hygiene, sharing bathing items and contact with infected persons), environmental factors (unimproved toilet facilities, poor housing, and overcrowding) and lack of access to prompt diagnostic tools are among the factors that have been postulated to facilitate the disease transmission $[13,14]$.

Several studies have shown spatial heterogeneity and clustering of the disease in endemic communities [15]. There is also evidence that a good proportion of nongenital ulcerative skin lesions in yaws endemic communities have multiple causative agents including Haemophilus ducreyi $[16,17]$. This calls for more research in understanding the epidemiology of the disease, particularly, the transmission process. There is currently no vaccine for yaws and the success of the eradication strategy is strongly linked to understanding the epidemiology of the disease, particularly the risk factors, since humans are the only known reservoirs. This study assessed the factors associated with cutaneous ulcers among children in two yaws-endemic districts in Ghana.

\section{Methods \\ Study design}

The study was a community-based unmatched 1:2 casecontrol study conducted in the Upper West Akyem and Awutu Senya West districts in the Eastern and Western Regions of Ghana respectively. The cases and controls were selected from households and schools within the same communities.

\section{Study areas}

The two selected districts for the study continue to record high numbers of cases of yaws despite numerous interventions. The Awutu Senya West and Upper West Akyem districts are located in the Central and Eastern Regions respectively. The two districts share a common boundary, with the Upper West Akyem district located at the northeastern border of the Awutu Senya West district. The total household population of both districts is a little over 80000 according to the 2010 population and housing census with children under the age of 15 years constituting more than $50 \%$ of the population.

High temperatures and humidity coupled with occasional heavy rainfall facilitate the transmission of yaws and other tropical diseases. The majority of the people live in rural areas, $52 \%$ in the Awutu Senya West district and 75\% in the Upper West Akyem district [18].

Overcrowding is a major problem in both districts. Single room occupancy is as high as $91 \%$ in the Upper West Akyem district with more than $10 \%$ of such rooms accommodating more than 10 persons. The average number of persons per house in both districts is seven [18].

Public toilet facilities are commonly used in both districts and a significant number of the populace engage in open defecation. More than $40 \%$ of residents in the rural communities of both districts use open bathing cubicles. 
A significant proportion of residents (about 20\%) in both districts lack access to potable water and resort to rivers and streams as their main source of water for drinking and other household chores. Mud brick/earth (32.1\%) is the second most important material used for outer walls of dwelling units in Awutu Senya West district. The proportion is slightly higher in the Upper West Akyem district (52.7\%) [18].

\section{Study population}

Children between ages 1-15 years who met the criteria for cases or control and resident in the Awutu Senya West and Upper West Akyem districts.

\section{Case definition}

The cases included in the study were cases with early or active yaws. Any child between the ages of 1-15 years who is resident in the Upper West Akyem or Awutu Senya West district who met the following criteria:

\section{Suspected case}

Presence of primary and secondary lesions: papillomata, painless ulcer or hyperkeratosis. The cases were examined and selected using the WHO picture guide (Fig. 1).

Primary Yaws lesions: 1 . Ulcers with raised edges and a crusty base or 2. Papilloma that appears as a firm yellowish skin lesion with a dark tip, on any part of the body.

Secondary Yaws lesions: Multiple ulcers or papillomata as previously defined, hyperkeratosis, macules, papules, nodules and maculopapular rash.

\section{Probable case}

A probable case was defined as any suspected case with only a positive rapid treponemal test. This test was done using the SD Bioline Syphilis 3.0 RDT.

\section{Confirmed case}

A probable case with a dually positive treponemal and non-treponemal test. Confirmation was done with rapid point of care (POC) test; The Dual Path Platform (DPP) Syphilis Screen and Confirm test kit (Chembio, Medford, NY, USA). The test kit has been shown to be highly specific and sensitive (95.2 and 92\% respectively) compared to traditional Treponemal assays [19]. Finger prick blood samples were used for the test. The DPP tests results were read qualitatively and independently by two trained field officers. In instances where the two results were conflicting, a third independent reading by a senior field officer was taken as conclusive.

\section{Controls}

Children aged between 1 and 15 years in the Awutu Senya West and Upper West Akyem districts without a history of yaws or yaws-like skin lesions and living in the same neighborhood as the cases.

\section{Sample size and data collection}

The total sample size for the study was 186 (62 cases and 124 controls) calculated assuming a power of $80 \%$ to detect an odds ratio of 3.0 with $18 \%$ exposure among controls [20] at an alpha level of 0.05 using OpenEpi Version 3 [21].

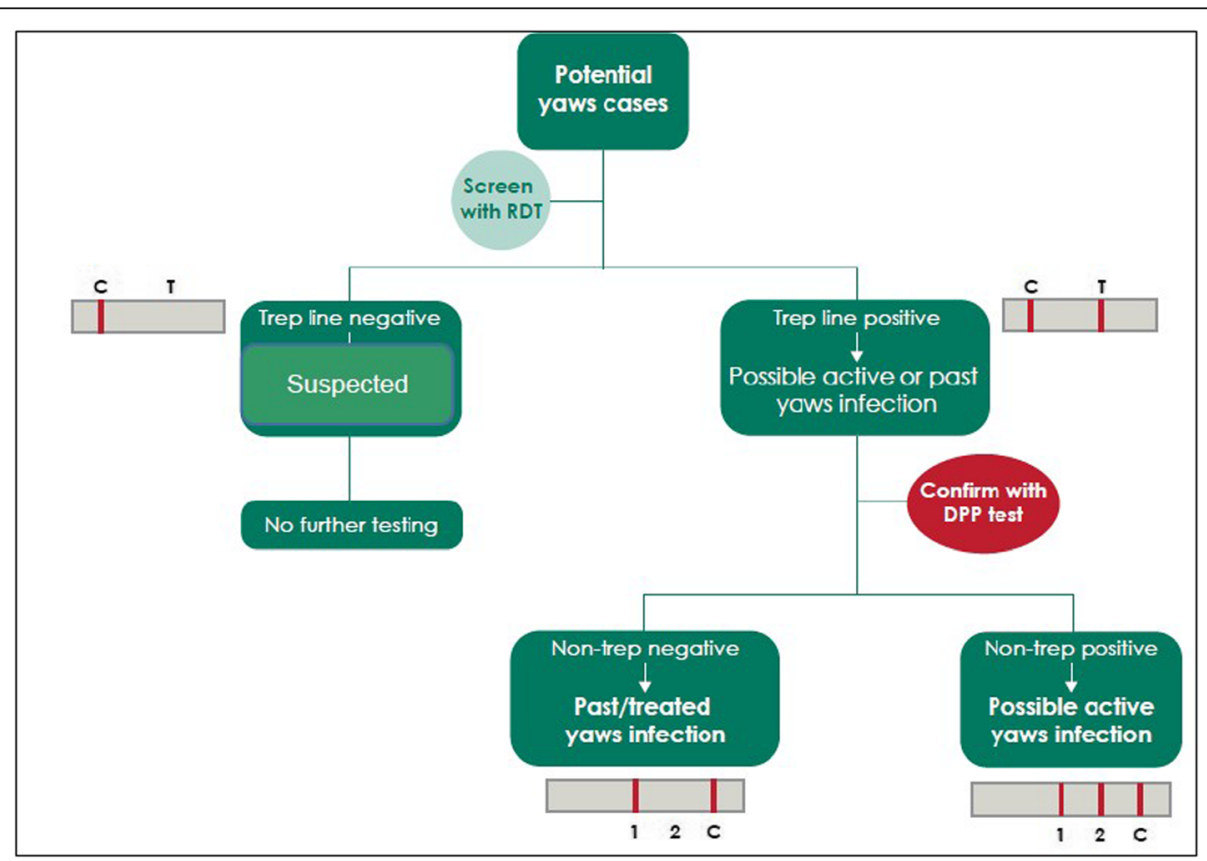

Fig. 1 Algorithm for case selection (adapted from the World Health Organization guidelines) 
Data on exposures among cases and controls were collected using a pre-coded structured interviewer-administered questionnaire designed using the Research Electronic Data Capture (REDCap ${ }^{\circ}$ data capture tools hosted at the University of Ghana [22]. The questionnaire assessed the socio-demographic, environmental and behavioral factors associated with the transmission of yaws. Previous yaws infection was ascertained verbally from caregivers.

\section{Case selection}

Trained research assistants, field officers and the principal investigator identified cases from communities and schools in the district through active search using the criteria above.

\section{Controls}

Controls were selected from the same communities as cases. Two controls were selected for each case. A cardinal point, that is, east, west, north or south was selected through balloting in the house of an identified case. The first two houses in the balloted direction were then selected. A control was then selected in each house. Numbers were assigned to all children who met the criteria for controls in the house. A number was selected through balloting and the participant was included in the study. If no eligible controls were found in a selected house, the next house in the same direction was selected and the process repeated.

Controls were also selected in schools in instances where cases were identified in schools. The controls were selected from the same class where the cases were found. The selection was done through balloting, all eligible controls in the identified class were included in the balloting process. The number of controls subsequently selected was based on the number of cases identified in the class using a case to control the ratio of $1: 2$.

\section{Data processing and analysis}

All data analysis was done with Stata 15 statistical software (StataCorp. 4905 Lakeway Drive Station, Texas 77 845, USA). Descriptive statistics were performed for all variables and expressed as means and standard deviation for continuous variables. Categorical variables were expressed as proportions and presented as graphs or charts where appropriate.

Univariable analysis (logistic regression) was done to test the association between socio-demographic factors, behavioral factors and yaws infection. This was presented as crude odds ratios with a $95 \%$ confidence interval. The final age and sex-adjusted multivariable logistic regression model fitted to determine the factors associated with yaws was done using backward stepwise approach (exposure variables with $P$ values $\leq 0.1$ were added and those with $P$ values $\geq 0.2$ were removed).
The analysis was done in two stages, initially with all cases (suspected, probable and confirmed) considered as a single group and then subsequently with only confirmed cases. The results description presented below represents all cases (suspected, probable and confirmed).

All statistical analysis was done at a 95\% significance level with $P$ values $<0.05$ considered as statistically significant.

\section{Results}

\section{Demographic characteristics of respondents}

One hundred and eighty-six participants were recruited in the two districts, comprising of 62 cases and 124 controls.

The age range of the study participants was between 3 and 15 years. Cases were older than controls. The median age of cases was 11 years and the median age of controls was 10 years. There was however no statistically significant difference between the ages $(P>0.05)$. There was no significant statistical difference between the ages of males and females. Majority of the study participants in both districts were between the ages of $10-15$ years, constituting more than half of participants in each district (Table 1).

\section{Type and distribution of yaws lesions}

Thirty-one cases were identified from each district. Half of the cases $(50.0 \%, 31 / 62)$ were classified as suspected cases, 4 cases $(6.5 \%)$ were classified as probable cases and 27 (43.6\%) were confirmed using the DPP rapid test kit (Table 2).

Majority of the lesions were ulcers $(67 \%, 42 / 62)$. The second most frequent lesion was papilloma (19.4\%, 12/ $62)$. The other types of lesions; papules, macules, hyperkeratosis and maculopapular rash were less frequent contributing to less than $5 \%$ of the total number of cases seen (Table 2 and Fig. 2).

\section{Socio-demographic factors associated with yaws transmission}

There was a significant association between sex and yaws infection. Yaws cases were two times more likely to be males $(\mathrm{cOR}=2.70,95 \% \mathrm{CI}: 1.38-5.26)$. The Ga/ Adangme $(\mathrm{cOR}=4.80,95 \% \mathrm{CI}: 1.23-18.63)$ and Ewe $(\mathrm{cOR}=4.95,95 \%$ CI: $1.31-18.66)$ ethnic groups had increased odds of yaws infection compared to the other ethnic groups (Table 3).

\section{Behavioral factors associated with yaws transmission}

Sharing of personal items such as towels and sponge (cOR $=3.10,95 \%$ CI: $1.40-6.97)$ and sharing a bathroom with more than five persons $(\mathrm{cOR}=2.57$, 95\% CI: $1.36-$ $4.80)$ were associated with active yaws infection. A previous contact with someone who had yaws was associated 
Table 1 Age and sex distribution of study participants

\begin{tabular}{|c|c|c|c|c|}
\hline & Controls $(n=124)$ & Cases $(n=62)$ & $P$-value & \\
\hline Age (median, IQR) & $10(8,13)$ & $11(9,13)$ & 0.076 & \\
\hline \multicolumn{5}{|l|}{$\operatorname{Sex}(n, \%)$} \\
\hline Male & $64(51.6)$ & $46(74.2)$ & $0.003^{\neq}$ & \\
\hline \multirow[t]{2}{*}{ Female } & $60(48.4)$ & $16(25.8)$ & & \\
\hline & Awutu Senya West & Upper West Akyem & & \\
\hline Age group & $n(\%)$ & $n(\%)$ & Total & $P$-value \\
\hline$<5$ years & $3(50.0)$ & $3(50.0)$ & 6 & 0.646 \\
\hline $5-9$ years & $29(45.3)$ & $35(54.7)$ & 64 & \\
\hline \multirow[t]{2}{*}{$10-15$ years } & $61(52.6)$ & $55(47.4)$ & 116 & \\
\hline & Males & Females & & \\
\hline Age group & N (\%) & N (\%) & Total & $P$-value \\
\hline$<5$ years & $2(33.3)$ & $4(66.7)$ & 6 & 0.222 \\
\hline $5-9$ years & $42(65.6)$ & $22(34.4)$ & 64 & \\
\hline 10-15 years & $66(56.9)$ & $50(43.1)$ & 116 & \\
\hline
\end{tabular}

${ }^{\mp} P<0.05$ means statistically significant

with yaws infection. Compared to community controls, yaws cases had increased odds of previous exposure to the disease $(\mathrm{cOR}=2.70,95 \% \mathrm{CI}: 1.42-5.11)$. Comparatively, cases were less likely to be fully clothed or dressed regularly (cOR $=2.76,95 \%$ CI: $1.15-6.59)$. Good hand washing practices was less frequent among cases compared to community controls. A greater proportion of cases compared to controls (cOR $=4.98,95 \%$ CI: $2.42-$ 10.27) reported that they did not wash their hands regularly when required (Table 3 ).

\section{Environmental factors associated with yaws transmission}

Yaws cases had increased odds of staying in a compound house compared to controls. Compared to community controls, cases had a three-fold increased odds of sharing a sleeping room with more than four persons $(\mathrm{cOR}=3.31$, 95\% CI: $1.71-6.41)$ or sharing a house with $5-8$ persons (cOR $=4.65,95 \%$ CI: $1.68-12.86)$ or more than eight persons (cOR $=6.78,95 \%$ CI: 2.24-20.50) (Table 3).

The factors associated with yaws from the adjusted analysis were residence in a compound house $(\mathrm{aOR}=$ 25.42, 95\% CI: 6.15-105.09), age (aOR $=5.90,95 \% C I$ : 1.97-17.67), male sex (aOR $=4.15,95 \%$ CI: 1.29-13.36), sharing a bathroom with more than five persons $(\mathrm{aOR}=$ 3.25, 95\% CI: 1.09-9.71) and poor hand washing habits $(\mathrm{aOR}=6.46,95 \%$ CI: $1.89-22.04)$ (Table 4). Table 5 summarizes factors that were not significantly associated with yaws transmission.

\section{Discussion}

Poor personal hygiene, overcrowding and lack of access to improved sanitary facilities are the major factors that facilitate the transmission of yaws in the Awutu Senya
West and Upper West Akyem districts. This is partly enhanced by the poor living standards in endemic communities in both districts.

Previous case-control studies conducted in Ghana by Dzotsi and colleagues showed no significant association between age and yaws [20]. In this study however, the adjusted analysis showed that increasing age was associated with increased odds of infection. This is similar to findings by Marks et al. [13]. Their sero-prevalence study demonstrated that increasing age was significantly associated with active disease [13]. Exposure to activities that can lead to trauma and abrasions tend to increase with age more especially among males. This increases the risk of infection with the bacterium. The injury sites serve as conducive environments and portals that facilitate the transmission of yaws.

Table 2 Yaws case classification and distribution in Upper West Akyem and Awutu Senya West districts

\begin{tabular}{|c|c|c|c|c|}
\hline \multirow[t]{2}{*}{ Variables } & \multicolumn{4}{|c|}{ Case category, $n(\%)$} \\
\hline & Suspected & Probable & Confirmed & Total \\
\hline \multicolumn{5}{|l|}{ Name of district } \\
\hline Awutu Senya West & $15(48.4)$ & $4(100)$ & $12(44.4)$ & 31 \\
\hline Upper West Akyem & $16(51.6)$ & $0(0)$ & $15(55.6)$ & 31 \\
\hline \multicolumn{5}{|l|}{ Type of lesion } \\
\hline Ulcer & $28(90.3)$ & $3(75)$ & $11(40.7)$ & $42(67.7)$ \\
\hline Papilloma & $2(6.5)$ & $1(25)$ & $9(33.3)$ & $12(19.4)$ \\
\hline Macules & - & - & $1(3.7)$ & $1(1.6)$ \\
\hline Papules & $1(3.2)$ & - & $1(3.7)$ & $2(3.2)$ \\
\hline Maculopapular rash & - & - & $3(11.1)$ & $3(4.8)$ \\
\hline Hyperkeratosis & - & - & $2(7.5)$ & $2(3.2)$ \\
\hline
\end{tabular}

- Not applicable. 


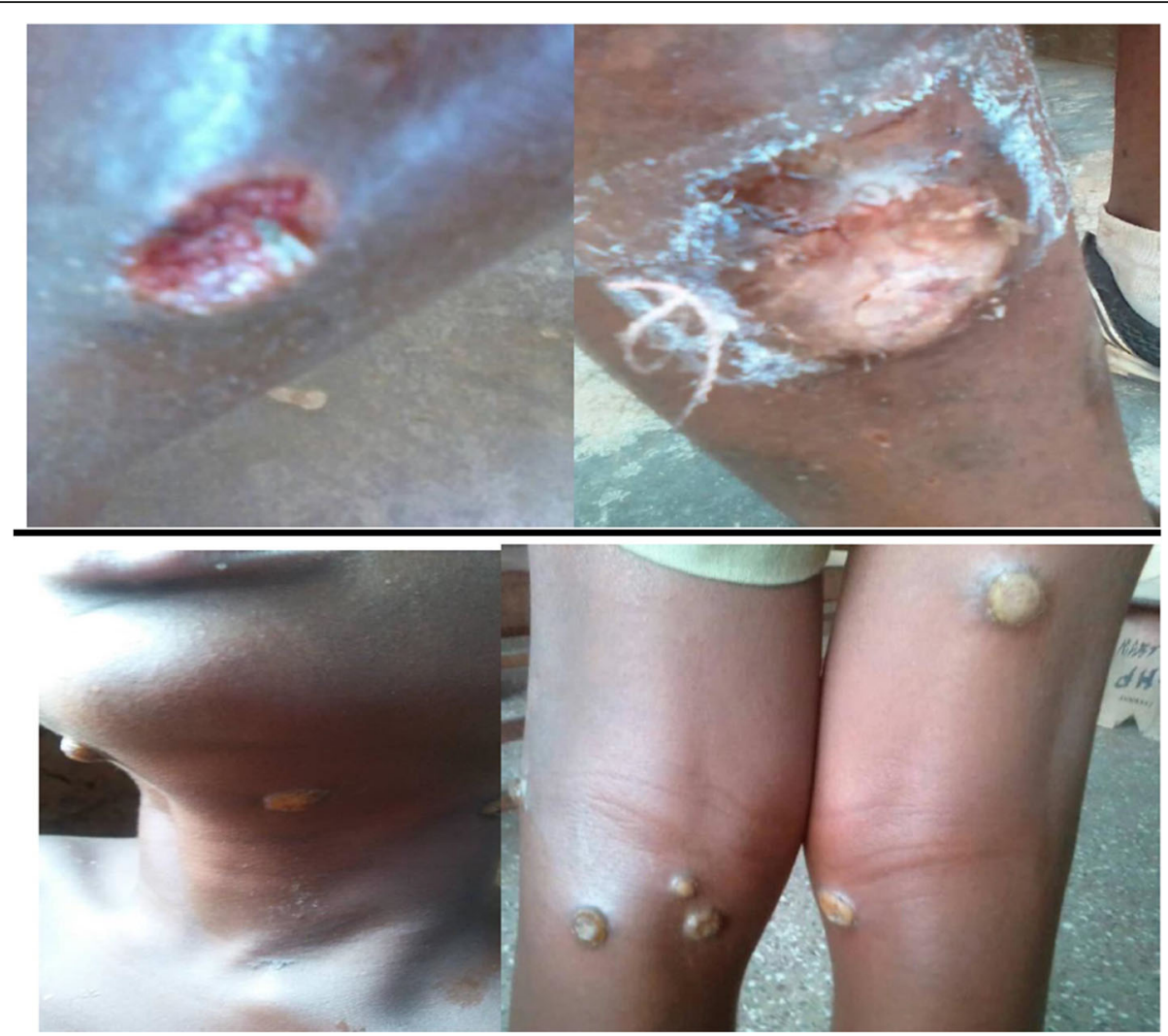

Fig. 2 Upper: Yaws ulcers showing the pathognomonic "punched out" edges; Lower: Multiple papilloma on the neck and lower limbs of two study participants

Previous infection with yaws does not result in long lasting immunity and individuals previously infected carry a significant risk of reinfection. This could possibly be as a result of reactivation of latent yaws in a previously untreated patient [6]. This study showed that yaws cases had a threefold increased odd of being previously infected. This confirms the fact that relapses of asymptomatic, infected individuals is a major factor that drives the reemergence of yaws particularly in communities that have benefited from control efforts [23]. The risk of reinfection is also enhanced by the fact that previously infected individuals continue to reside in highly endemic communities which puts them at an increased risk. Marks and colleagues demonstrated a strong association between the degree of village endemicity and active yaws infection [10].

Infected persons serve as important reservoirs for continuous transmission of yaws. Thus, contact with an infected person significantly increases the risk of infection. Asymptomatic individuals with latent yaws infection also serve as potential sources of the reintroduction of infection into the community [23]. In this study, yaws patients had almost five fold-increased odds of previous contact or exposure to yaws. Transmission of yaws occurs through contact with infected fluid from lesions.
The univariable analysis showed that the risk of infection was higher among study participants who share personal items like towels and sponge or use bathrooms shared by more than four persons.

Lack of access to proper sanitation such as potable drinking water, appropriate waste disposal facilities and toilet facilities facilitate the transmission of yaws [24]. We also found an increased risk of yaws transmission among persons who do not wash their hands regularly. From our study, more than half of the participants indicated a source of water within 5 minutes from their place of residence. This suggest that water is available to them. The worrying observation, therefore, is the fact that about eight in every ten cases admittedly do not wash their hands with soap. This brings to light the inadequacy of behavior change component in water sanitation and hygiene (WASH) programs being implemented. In recent times, efforts have been made to foster collaboration between WASH and NTD control programs for desired impacts. Key among them is the meeting involving WASH and NTD experts which was organized by Emory University in the USA and the Task Force for Global Health. The group agreed on a common vision, namely "Disease-free communities that have adequate and equitable access to water and sanitation, and that 
Table 3 Summary of univariate analysis - Factors significantly associated with yaws (All cases and confirmed cases)

\begin{tabular}{|c|c|c|c|c|}
\hline \multirow[t]{2}{*}{ Variables } & \multicolumn{2}{|l|}{ All cases } & \multicolumn{2}{|l|}{ Confirmed cases } \\
\hline & $\mathrm{COR}(95 \% \mathrm{Cl})$ & $P$-value & COR $(95 \% C l)$ & $P$-value \\
\hline \multicolumn{5}{|l|}{ Socio-demographic factors } \\
\hline Sex (Male) & $2.70(1.38-5.26)$ & 0.004 & $2.70(1.12-6.49)$ & 0.027 \\
\hline Ethnicity (Ga/Adangme) & $4.80(1.23-18.63)$ & 0.023 & NS & \\
\hline Ethnicity (Ewes) & $4.95(1.31-18.66)$ & 0.018 & $9.68(1.18-79.09)$ & 0.034 \\
\hline Past treatment for yaws (Yes) & $2.7(1.13-6.47)$ & 0.025 & $3.48(1.26-9.60)$ & 0.016 \\
\hline \multicolumn{5}{|l|}{ Behavioral factors } \\
\hline Bath every day (No) & $2.76(1.31-5.80)$ & 0.008 & $4.50(1.87-10.84)$ & 0.001 \\
\hline Frequency of bathing/day (Once) & $1.98(1.07-3.68)$ & 0.03 & $3.50(1.49-8.21)$ & 0.004 \\
\hline Sharing of towels/sponge (Yes) & $3.10(1.40-6.97)$ & 0.005 & $3.50(1.17-10.94)$ & 0.025 \\
\hline Bathroom (used by $>5$ persons) & $2.57(1.36-4.80)$ & 0.003 & NS & \\
\hline Contact with yaws (Yes) & $2.70(1.42-5.11)$ & 0.002 & $5.23(2.26-12.09)$ & $<0.0001$ \\
\hline Use of clothing (Not regularly) & $2.76(1.15-6.59)$ & 0.022 & NS & \\
\hline Handwashing (Not regularly) & $4.98(2.42-10.27)$ & $<0.0001$ & $4.10(1.65-10.22)$ & 0.002 \\
\hline \multicolumn{5}{|l|}{ Environmental factors } \\
\hline Type of housing (Compound ${ }^{\mathrm{a}}$ ) & $2.91(1.53-5.50)$ & 0.001 & $4.74(1.90-11.84)$ & 0.001 \\
\hline Sleeping room occupancy (> 4 persons) & $3.31(1.71-6.41)$ & $<0.001$ & $4.5(1.20-10.49)$ & $<0.0001$ \\
\hline House occupancy (> 8 persons) & $6.78(2.24-20.50)$ & 0.001 & $6.22(1.57-24.63)$ & 0.009 \\
\hline Toilet facility (open defecation) & $2.70(1.25-6.16)$ & 0.012 & $3.70(1.37-10.04)$ & 0.01 \\
\hline
\end{tabular}

cOR Crude odds ratio, Cl Confidence interval, NS No statistical significance; ${ }^{a}$ compound house - housing structure with multiple households ( $>2$ ) with shared facilities (cooking, bathing, toilets)

practice good hygiene" [25]. It is therefore important that this commitment is backed by implementation strategies with the well-crafted and well-tailored behavioral change effort.

The observation that persons living in compound houses are at increased risk of yaws is consistent with other studies. It is well established that persons living in compound houses belong largely to the low-socioeconomic groups and in most instances, are overcrowded. It is also evident from the literature that yaws thrive in socio-economically disadvantaged communities where overcrowding is common. According to Mackey and colleagues, staying in a compound house, sharing a sleeping room with more than four persons or staying in an overcrowded house significantly increases the risk of yaws transmission [24]. This is attributed to the fact that the mode of yaws transmission is through skin contact with an infected person. In compound houses, there is high interaction amongst the people and therefore, the risk of transmission of yaws can occur when individuals with active yaws lesions come into close contact with other people by sharing bathrooms and or sleeping together as was observed in our study. In a cluster randomized study by Marks et al., in the Solomon Islands, Treponema pallidum particle agglutination assay (TPPA) positivity and dual sero-positivity were associated with increased number of dual positive household contacts [13]. Similar studies have also found this significant association of yaws and environmental factors such as overcrowding [20, 26-28].

Table 4 Multivariate analysis of factors associated with yaws (all cases) in the Upper West Akyem and Awutu Senya West districts

\begin{tabular}{|c|c|c|c|}
\hline Variables & $\mathrm{a} O R$ & $95 \% \mathrm{Cl}$ & $P$-value \\
\hline Age (years) & 5.90 & $1.97-17.67$ & $0.002^{\ddagger}$ \\
\hline Sex (Male) & 4.15 & $1.29-13.36$ & $0.039^{\ddagger}$ \\
\hline Handwashing (Not regularly) & 6.46 & $1.89-22.04$ & $0.003^{\ddagger}$ \\
\hline Number of persons sharing a bathroom ( $>5$ persons) & 3.25 & $1.09-9.71$ & $0.035^{\ddagger}$ \\
\hline Type of toilet facility (open defecation) & 3.59 & $0.99-12.99$ & 0.052 \\
\hline Type of housing (Compound house) ${ }^{a}$ & 25.42 & $6.15-105.09$ & $<0.0001^{\ddagger}$ \\
\hline Sleeping room occupancy (> 4 persons) & 2.60 & $0.79-8.58$ & 0.117 \\
\hline
\end{tabular}

${ }^{\ddagger} P<0.05$ means statistically significant; aOR Adjusted odds ratio; ${ }^{a}$ compound house - housing structure with multiple households ( $>2$ ) with shared facilities (cooking, bathing, toilets) 
Table 5 Summary of univariate analysis- Factors not significantly associated with yaws (all cases)

\begin{tabular}{lll}
\hline Variables & $\operatorname{COR}(95 \%$ Cl) & $P$-value \\
\hline Level of education of caregiver & & - \\
None & ref & 0.83 \\
Primary & $1.1(0.48-2.50)$ & 0.866 \\
Junior High School & $0.92(0.36-2.36)$ & 0.962 \\
Senior High School & $1.05(0.17-6.60)$ & \\
Bathing with soap & & - \\
Yes & ref & 0.99 \\
No & $0.99(0.23-4.11)$ &
\end{tabular}

Building material

Cement block

ref

Mud

$1.06(0.51-2.0)$

Source of water for household activities

Pipe borne water

Bore hole

$0.58(0.12-2.66)$

Well

$1.63(0.55-4.78)$

0.484

0.375

Streams/rivers/ponds

$1.52(0.59-3.96)$

Distance from water source

$<5$ min

ref

5-10 min

$1.69(0.60-4.27)$

0.352

$>10$ min

$1.81(0.68-4.85)$

0.236

COR Crude odds ratio, $\mathrm{Cl}$ Confidence interval

The choice of case-control study design could amount to recall bias particularly among the controls. Also, swabs from yaws-like ulcers in some endemic areas have shown infections with Haemophilus ducreyi alone or coinfections with T. pallidum subspecies pertenue and $H$. ducreyi $[9,11,16,17,29]$. The prevalence of substandard sanitary and personal hygienic conditions in yaws-endemic communities also facilitates the persistence of $H$. ducreyi infections in these communities [29]. The presence of $H$. ducreyi in lesions was however not determined in this study. Finally, prevalence-incidence bias is encountered in case control studies where exposures may rather tend to be protective typically when the disease involved is chronic. To reduce this, incident cases (active disease) were included in the study.

\section{Conclusions}

Poor personal hygiene, overcrowding and lack of access to improved sanitary facilities are the factors associated with the transmission of yaws in the Awutu Senya West and Upper West Akyem districts. The skin lesions were also more common among males and school-aged children. Improving living conditions, access to good sanitary facilities and encouraging good personal hygiene practices should be core features of eradication programs in endemic communities.

\section{Abbreviations}

DPP: Dual Path Platform; GHS-ERC: Ghana Health Service Ethics Review Committee; NTD: Neglected tropical disease; NYEP: National Yaws Eradication Program; POC: Point of care; RDT: Rapid diagnostic test; WASH: Water sanitation and hygiene; WHO: World Health Organisation

\section{Acknowledgments}

We wish to acknowledge the respondents of this study for their time.

\section{Authors' contributions}

RNAO, BS, RMA and CKM conceptualized and designed the study, developed tools for data collection, supervised data collection and analyzed the data. RNAO and FAO drafted the initial manuscript and was subsequently reviewed by all authors. All authors approved the final manuscript and agreed to be accountable for all aspects of the work before it was finally submitted.

\section{Authors' information}

Not applicable.

\section{Funding}

The work was funded under the WHO/TDR Implementation Science Fellowship Program.

\section{Availability of data and materials}

The data collected for the study which has been analyzed and presented are available at the first authors' institution and is available upon formal request.

\section{Ethics approval and consent to participate}

The study was explained to the participants and caregivers in clear and unambiguous language. Written informed consent and assent were obtained before inclusion in the study. Ethical approval was obtained from the Ghana Health Service Ethics Review Committee (GHS-ERC: 034/12/18) and permission was sought from the District Health and Educational directorates.

Consent for publication

Not applicable.

\section{Competing interests}

The authors declare that they have no competing interests.

\section{Author details}

${ }^{1}$ World Health Organization (WHO), Country Office for Ghana, Accra, Ghana. 2Department of Epidemiology and Disease Control, School of Public Health, College of Health, Sciences, University of Ghana, Accra, Ghana. ${ }^{3}$ Department of Population, Family and Reproductive Health, School of Public Health, College of Health, Sciences, University of Ghana, Accra, Ghana. ${ }^{4}$ National Program Office, National Yaws Eradication Program (NYEP), Accra, Ghana.

${ }^{5}$ Public Health Unit, Komfo-Anokye Teaching Hospital, Kumasi, Ghana.

${ }^{6}$ KNUST School of Public Health, Kumasi, Ghana.

Received: 26 November 2019 Accepted: 21 February 2020

Published online: 12 March 2020

\section{References}

1. Marks M, Mitjà O, Vestergaard LS, Pillay A, Knauf S, Chen C, et al. Challenges and key research questions for yaws eradication. Lancet. 2015;15:1220-5.

2. Mitjà O, Marks M, Konan DJP, Ayelo G, Gonzalez-beiras C, Boua B, et al. Global epidemiology of yaws : a systematic review. Lancet Glob Heal. 2015; 3:324-31.

3. Asiedu K, Fitzpatrick C, Jannin J. Eradication of yaws : Historical efforts and achieving WHO 's 2020 Target. PLoS Negl Trop Dis. 2014;8(9):e3016.

4. Ayove T, Houniei W, Wangnapi R, Bieb SV, Kazadi W, Luke L, et al. Sensitivity and specifi city of a rapid point-of-care test for active yaws : a comparative study. Lancet Glob Heal. 2014;2:415-21.

5. NYEP. Fact sheet on yaws in Ghana. 2017.

6. Agana-nsiire P, Kaitoo E, Erasmus E, Agongo A, Bonsu G, Kyei-faried S, et al. Yaws prevalence, lessons from the field and the way forward towards yaws eradication in Ghana. Int Sch Res Not. 2014;2014:1-17.

7. Kwakye-Maclean C, Agana N, Gyapong J, Nortey P, Adu-Sarkodie Y, Aryee E, et al. A single dose oral azithromycin versus intramuscular benzathine 
penicillin for the treatment of yaws-a randomized non inferiority trial in Ghana. PLoS Negl Trop Dis. 2017;11(1):e0005154.

8. Abdulai AA, Agana-Nsiire P, Biney F, Kwakye-Maclean C, Kyei-Faried S, Amponsa-Achiano K, et al. Community-based mass treatment with azithromycin for the elimination of yaws in Ghana-Results of a pilot study. PLoS Negl Trop Dis. 2018;12(3):e0006303.

9. Mitjà O, Houinei W, Moses P, Kapa A, Paru R, Hays R, et al. Mass treatment with single-dose azithromycin for yaws. N Engl J Med. 2015;372(8):703-10.

10. Marks M, Vahi V, Sokana O, Chi KH, Puiahi E, Kilua G, et al. Impact of community mass treatment with azithromycin for trachoma elimination on the prevalence of yaws. PLoS Negl Trop Dis. 2015;9(8):e0003988.

11. Mitjà O, Godornes C, Houinei W, Kapa A, Paru R, Abel H, et al. Reemergence of yaws after single mass azithromycin treatment followed by targeted treatment: a longitudinal study. Lancet. 2018;391(10130):1599-607.

12. Amin R, Sattar A, Basher A, Faiz MA. Eradication of yaws. J Clin Med Res. 2010;2:49-54.

13. Marks M, Vahi V, Sokana O, Puiahi E, Pavluck A, Zhang Z, et al. Mapping the epidemiology of yaws in the Solomon Islands : a cluster randomized survey. Am J Trop Med Hyg. 2015;92(1):129-33.

14. Kazadi W, Asiedu K, Nsiire A, Mitja O. Epidemiology of yaws : an update. Clin Epidemiol. 2014;6:119-28.

15. Mooring EQ, Mitjà O, Murray MB. Spatial-temporal clustering analysis of yaws on Lihir Island, Papua New Guinea to enhance planning and implementation of eradication programs. PLoS Negl Trop Dis. 2018;12(10): e0006840.

16. Ghinai R, El-Duah P, Chi KH, Pillay A, Solomon AW, Bailey RL, et al. A crosssectional study of 'yaws' in districts of Ghana which have previously undertaken azithromycin mass drug administration for trachoma control. PLoS Negl Trop Dis. 2015;9(1):e0003496.

17. González-Beiras C, Marks M, Chen CY, Roberts S, Mitjà O. Epidemiology of Haemophilus ducreyi infections. Emerg Infect Dis. 2016;22(1):1-8.

18. Service GS. Population and housing census report. 2010.

19. Marks M, Goncalves A, Vahi V, Sokana O, Puiahi E, Zhang Z, et al. Evaluation of a rapid diagnostic test for yaws infection in a community surveillance setting. PLoS Negl Trop Dis. 2014:8(9):e3156.

20. Dzotsi E, Agana N, Ohene SA, Adjabeng M, Aziz A, Odoom JK. Factors associated with yaws infections in the west Akim municipality, Ghana. Int $J$ Trop Dis Heal. 2017;22(3):1-9.

21. Sullivan KM, Dean A, Minn MS. OpenEpi: a web-based epidemiologic and statistical calculator for public health. Public Health Rep. 2009;124:471-4.

22. Harris PA, Taylor R, Thielke R, Payne J, Gonzalez N, Conde JG. Research electronic data capture (REDCap)-a metadata-driven methodology and workflow process for providing translational research informatics support. J Biomed Inform. 2009:42(2):377-81.

23. Mitjà O, Asiedu K, Mabey D. Yaws. Lancet. 2013;381 (9868):763-73.

24. Mackey TK, Liang BA, Cuomo R, Hafen R, Brouwer KC, Lee DE. Emerging and reemerging neglected tropical diseases : a review of key characteristics, risk factors, and the policy and innovation environment. Clin Microbiol Rev. 2014;27(4):949-79.

25. Freeman MC, Ogden S, Jacobson J, Abbott D, Addiss DG, Amnie AG, et al. Integration of water, sanitation, and hygiene for the prevention and control of neglected tropical diseases: a rationale for inter-sectoral collaboration. PLoS Negl Trop Dis. 2013;7(9):e2473.

26. Tettey A. School of public health, college of health sciences, University of Ghana-Legon, factors associated with yaws in the Ga west district of Ghana ( a case-control study at Obom); 2009

27. Kwakye-maclean C, Agana N, Gyapong J, Nortey P. A single dose oral azithromycin versus intramuscular benzathine penicillin for the treatment of yaws-a randomized non inferiority trial in Ghana. PLoS Negl Trop Dis. 2017; 11(1):e0005154.

28. Dyson L, Marks M, Crook OM, Sokana O, Solomon AW, Bishop A, et al. Targeted treatment of yaws with household contact tracing: how much do we miss? Am J Epidemiol. 2018;187(4):837-44.

29. Houinei W, Godornes C, Kapa A, Knauf S, Mooring EQ, González-Beiras C, et al. Haemophilus ducreyi DNA is detectable on the skin of asymptomatic children, flies and fomites in villages of Papua New Guinea. PLoS Negl Trop Dis. 2017;11(5):e0004958.

Ready to submit your research? Choose BMC and benefit from:

- fast, convenient online submission

- thorough peer review by experienced researchers in your field

- rapid publication on acceptance

- support for research data, including large and complex data types

- gold Open Access which fosters wider collaboration and increased citations

- maximum visibility for your research: over $100 \mathrm{M}$ website views per year

At BMC, research is always in progress.

Learn more biomedcentral.com/submissions 